\title{
Mismatch between perceived and actual overweight in diabetic and non-diabetic populations: a comparative study of South Asian and European women
}

\author{
S Patel, R Bhopal, N Unwin, M White, Sir K G M M Alberti, J Yallop
}

Diabetes is more common in South Asian (defined here as Indian, Pakistani and Bangladeshi origin) populations compared with Europeans. This may be related to their greater abdominal obesity. ${ }^{1}$ Weight loss and maintenance are crucial in the prevention of noninsulin dependent diabetes mellitus and motivation to loose weight is likely to be greater in those who perceive themselves as being overweight. We compared self perception of body weight using data on South Asian and European women (data unavailable for European men) from a population based study in Newcastle upon Tyne, UK. ${ }^{2}$

\section{Department of \\ Epidemiology and \\ Public Health, \\ University of \\ Newcastle \\ S Patel \\ R Bhopal \\ $\mathrm{N}$ Unwin \\ $M$ White \\ K G M M Alberti}

Human Diabetes and Metabolism Research Centre, University of Newcastle

S Patel

$\mathrm{N}$ Unwin

K G M M Alberti

J Yallop

Correspondence to: Miss Patel, Department of Medicine, School of Clinical Medical Sciences, University of Newcastle, Medical School, Framlington Place,

Newcastle upon Tyne NE2 $4 \mathrm{HH}$, UK

(Sheila.Patel@ncl.ac.uk)

Accepted for publication 14 December 2000

\begin{abstract}
Methods
Age stratified random samples of South Asian and European women aged 25-74 were taken from the Family Health Service Authority register. Altogether 589 South Asian and 682 European women were contacted. From these 371 South Asian and 399 European women were screened giving a response rate of $63.0 \%$ and $58.5 \%$ respectively. Of these, 319 South Asian and 382 European women had a standard World Health Organisation (WHO) oral glucose tolerance test. Prevalence of impaired glucose tolerance (IGT) and diabetes were based on two hour plasma glucose values according to WHO definitions ${ }^{3}: \geqslant 7.8$ and < $11.1 \mathrm{mmol} / 1$ for IGT; $\geqslant 11.1 \mathrm{mmol} / 1$ for diabetes. Known diabetes and self perception of body weight were identified by questionnaire. Subjects were asked, "for someone of your height, do you think you are: very underweight, a little underweight, about the right weight, a little overweight, very overweight." Europeans self completed the questionnaire. For the South Asians, the questionnaires were translated into South Asian languages and then back translated into English until equivalence
\end{abstract}

of meaning was achieved. South Asian women were interviewed in their own home in their preferred language. ${ }^{2}$

We compare those who perceived themselves as the right weight with actual overweight and abdominal obesity in normoglycaemic, previously unknown diabetes and IGT and known diabetes groups. Actual overweight (body mass index $(\mathrm{BMI}) \geqslant 25 \mathrm{~kg} / \mathrm{m}^{2}$ ) was defined according to WHO definitions ${ }^{4}$ and abdominal obesity was defined as a waist circumference $\geqslant 80$ $\mathrm{cm} .^{5}$ Analysis was carried out using the Statistical Package for Social Scientists (SPSS). ${ }^{2}$ All figures were age adjusted by weighting to the 1991 England and Wales population census using SPSS. Differences in proportions were assessed using the $\chi^{2}$ statistic and confidence intervals were calculated using Confidence Interval Analysis software (BMJ Publishing, London).

\section{Results}

South Asians are a heterogeneous group, ${ }^{2}$ and in this study consisted of Indian, Pakistani and Bangladeshi women. All analyses were performed separately in these groups but self perception as the right weight was similar (Indian (32\%), Pakistani (37\%) and Bangladeshi $(38 \%)$ therefore further analyses was carried out on South Asian women as one group.

Compared with Europeans, a significantly $(p<0.001)$ higher proportion of South Asian women were overweight $(64.9 \%$ v $52.4 \%, 95 \%$ CI for the difference, 5.6 to 19.4 ) had abdominal obesity $(71.0 v 40.6,(23.7$ to 37.1$) \%)$ and previously undiagnosed diabetes and IGT (26.6 v 14.4, (6.4 to 18) \%) as well as known diabetes (13.0 $v 2.1$, (7 to 14.8$) \%)$. Among those who perceived themselves as the right weight (table 1), a significantly higher ( $p$ $<0.001$ ) proportion of South Asian compared

Table 1 Proportions of South Asian (SA) and European (EU) women who perceived themselves as the right weight and the proportion of these who were actually overweight and had abdominal obesity, in normoglycaemic, previously unknown diabetes and IGT and known diabetes groups (analysis on non-missing observations)

\begin{tabular}{|c|c|c|c|c|c|c|c|c|}
\hline & \multicolumn{2}{|l|}{ All $\neq$} & \multicolumn{2}{|c|}{ Normoglycaemia } & \multicolumn{2}{|c|}{$\begin{array}{l}\text { Previously unknown } \\
\text { diabetes/IGT }\end{array}$} & \multicolumn{2}{|c|}{ Known diabetes } \\
\hline & $S A$ & $E U$ & $S A$ & $E U$ & $S A$ & $E U$ & $S A$ & $E U$ \\
\hline Total number $(\mathrm{n})$ & 366 & 371 & 213 & 326 & 94 & 56 & 46 & 8 \\
\hline Perception as the right weight (n (\%)) & $137(37.4)$ & $79(21.2)$ & $93(44.1)$ & $68(22.1)$ & $28(30.4)$ & $10(18.9)$ & $13(27.7)$ & - \\
\hline \multicolumn{9}{|c|}{ Among those perceiving themselves as the right weight: } \\
\hline${ }^{\star} \mathrm{n}(\%)$ actually overweight $\left(\mathrm{BMI} \geqslant 25 \mathrm{~kg} / \mathrm{m}^{2}\right)$ & $60(43.5)$ & $5(6.3)$ & $38(40.4)$ & $2(2.9)$ & $15(53.6)$ & $3(30.0)$ & $6(46.2)$ & - \\
\hline tn $(\%)$ with abdominal obesity (waist $\geqslant 80 \mathrm{~cm}$ ) & $75(55.6)$ & $9(11.3)$ & $45(48.9)$ & $4(5.8)$ & $18(64.3)$ & $5(50.0)$ & $12(92.3)$ & - \\
\hline
\end{tabular}

$\star$ Proportion $(\%)$ of overweight $\left(\mathrm{BMI} \geqslant 25 \mathrm{~kg} / \mathrm{m}^{2}\right)$ in those who perceived themselves as the right weight.

†Proportion $(\%)$ of abdominal obesity (waist $\geqslant 80 \mathrm{~cm}$ ) in those who perceived themselves as the right weight.

$\ddagger$ The numbers in the all group are the total number of South Asian and European women who responded to the questionnaire question of "for someone of your height, do you think you are: very underweight, a little underweight, about the right weight, a little overweight, very overweight". 
with European women were overweight (43.5 v 6.3, (27.3 to 47.0$) \%$ ) and had abdominal obesity (55.6 $v 11.3$, (33.4 to 55.2 ) \%). Ethnic differences in perceptions of being the right weight were seen in the normoglycaemic, previously unknown diabetes/IGT and known diabetes groups. More South Asian compared with European women who perceived themselves as the right weight and who had previously undiagnosed diabetes and IGT were actually overweight (53.6 $v 30.0 \%)$ and had abdominal obesity (64.3 $v 50.0 \%)$ but this difference was not significant $(p>0.05)$. Similar patterns were seen in South Asian women with known diabetes.

\section{Discussion}

There are major differences in awareness of obesity in South Asian women. Known diabetic patients could be expected to have more realistic body weight perception as a result of diabetes education. However, differences in self perception of obesity existed in normoglycaemic, previously unknown diabetes and IGT and known diabetes groups. Although the differences were not significant because of small numbers among the previously unknown diabetes and IGT and known diabetes groups it was still evident that there was greater awareness of obesity among the European compared with South Asian women. Reduction of obesity is crucial in the prevention and management of diabetes and appropriate education and awareness of obesity needs to be given to South Asian communities. Differences in self perception that may be attributable to differences in knowledge, beliefs and social circumstances need to be taken into account when designing preventative and treatment interventions in South Asians.

We thank all members of the Newcastle Heart Project Team who assisted with the project (they are listed in reference 2).

Funding: this study was supported by grants from the Barclay Trust, British Diabetic Association, Newcastle Health Authority and the Department of Health.

Conflicts of interest: none.

1 McKeigue PM. Metabolic consequences of obesity and body fat pattern: lessons from migrant studies. In: Chadwick DJ, Cardew GC, eds. The origins and consequences of obesity. (Ciba Foundation Symposium 201). Chichester: Wiley, 1996:54-67.

2 Bhopal R, Unwin N, White $\mathrm{M}$, et al. Heterogeneity of coronary heart disease risk factors in Indian, Pakistani, Bangladeshi, and European origin populations: cross sectional study. BMF 1999;319:215-20.

3 World Health Organisations. Diabetes mellitus: report of a study group. Technical Report Series no 727. Geneva: World Health Organisation, 1985.

4 Anonymous. Obesity, preventing and managing the global epidemic. Report of a WHO Consultation on Obesity. Geneva: WHO, 1997.

5 Han TS, van Leer EM, Seidell JC, et al. Waist circumference action levels in the identification of cardiovascular risk factors: prevalence study in a random sample. BMF 1995; 31:1401-5. 